\title{
Da relação ética e tecnologia em discursos exemplares: o caso das práticas baseadas em evidências
}

Flávia Regina Souza Ramos ${ }^{1}$

O texto propõe uma reflexão sobre a relação ética e tecnologia a partir de uma problematização focada nas práticas/enfermagem baseada em evidências. Tal tecnologia é tomada como exemplar por considerá-la um discurso potente na sua capacidade de definir modos de ser profissional e de propor um projeto educacional ou de ampla socialização de futuros profissionais. Discursos e tecnologias representativos do atual e complexo cenário de integração educação-trabalho no campo da saúde, como o eleito neste texto, devem ser analisados do ponto de vista ético, uma vez que participam da constituição do sujeito trabalhador, mediando suas relações com o outro e consigo mesmo.

Descritores: Enfermagem baseada em evidências; Ética; Enfermagem.

\section{The relation between ethics and technology in exemplary speeches: the case of evidence-based practices}

The text proposes a reflection on the relation between ethics and technology from a questioning focused on the evidence-based nursing/practices. Such technology is taken as exemplary because it considers these practices a powerful speech in its ability to define professional behaviors and to propose an educational project or comprehensive socialization for future practitioners. Speeches and technologies representative of the current and complex scenario of education/work integration in the health area, like the elected for this text, must be analyzed from an ethical point of view, since they take part on the construction of the employee, mediating their relations with others and themselves.

Descriptors: Evidence-based nursing; Ethics; Nursing.

\section{La relación entre la ética y la tecnología en discursos ejemplares: el caso de las prácticas basadas en la evidencia}

El texto propone una reflexión sobre la relación entre la ética y la tecnología desde un cuestionamiento centrado en la práctica/enfermería basada en evidencias. Esta tecnología se toma como ejemplar, teniendo en cuenta que considera estas prácticas un discurso potente en su capacidad para definir maneras de ser profesional y de proponer un proyecto educativo o la socialización integral de los futuros profesionales.

Discursos y tecnologías representantes del actual y complejo escenario de integración educación-trabajo en de en el campo de la salud, como el elegido en el texto, deben ser analizados desde un punto de vista ético, ya que participan de la constitución del sujeto trabajador, mediando en sus relaciones con los demás y él mismo.

Descriptores: Enfermería basada en la evidencia; Ética; Enfermería.

\section{INTRODUÇÃO}

ए ste texto parte de uma premissa inicial, a de que atuamos hoje em cenários complexificados de integração educaçãotrabalho no campo da saúde. Muitos podem ser os focos de análise reveladores de tal complexidade e o que se adota aqui é o da relação ética e tecnologia. Neste cenário, desenvolvemse os processos de formação profissional e parece evidente que, a par das grandes mudanças tecnológicas que se processam, três tradicionais referências não se perderam no tempo e mantêm-se com certa regularidade. São elas:

- uma prática e uma formação que se faz junto ao real, "em numerosas situações" ou exercícios práticos que usam o recurso às formas próprias de raciocinar, apoiadas em modelos;

- que habilidades e competências são adquiridas neste "fazer" (o mais precoce possível), seguindo o exemplo e as lições de quem já é o "bom profissional", enfim, desenvolvendo técnicas de leitura de elementos (dos corpos, da experiência anterior, dos saberes disponíveis) que se oferecem para serem acessados, manipulados, atualizados (constatados e corroborados, ou confrontados e desacreditados) e sempre adicionados a um acervo;

- neste fazer se forma o sujeito profissional, como uma "identidade", um modo de se perceber/se experienciar (e ser percebido), um reconhecimento de si como "ser profissional", diferenciado de outros sujeitos.

Assim, trata-se de aprofundar, a partir da análise de situações mais concretas, o que já foi levantado na tese de que a formação ética/bioética do trabalhador da saúde é indissociável de um conjunto de dispositivos pedagógicos que relacionam o mundo do trabalho e o mundo da escola em modos de ser profissional (1). Agora, o foco sobre a formação ética/bioética será atenuado e dirigido para a tecnologia mesma - uma tecnologia emergente, escolhida como exemplar nesta relação trabalho-educação. Exemplar na forma como interage/media a constituição deste sujeito trabalhador, ou por meio da qual o trabalhador se coloca em relações com o outro e consigo mesmo.

A tecnologia abordada é Enfermagem Baseada em Evidências (EBE), fundada a partir de seu correlato, a Medicina Baseada

1 Enfermeira. Doutora em Filosofia em Enfermagem (UFSC). Pós-Doutorada em Educação (Universidade de Lisboa). Professora Associada do Departamento de Enfermagem e Programa de Pós-Graduação em Enfermagem da UFSC. Pesquisadora CNPq. Coordenadora do Grupo de Pesquisa Práxis: Trabalho, Cidadania, Saúde e Enfermagem. 
em Evidências (MBE), e de outras tantas incorporações que fazem proliferar a adjetivação "baseada em evidências" (BE) em práticas como as de saúde pública, promoção da saúde, decisão do paciente ${ }^{(2)}$, ou a síntese "Práticas Baseadas em Evidências (PBE). O movimento da $\mathrm{MBE}$, de emergência localizada nos anos 90, tem demonstrado uma tendência de expansão para além das fronteiras da prática médica, com um impacto considerável e não na mesma medida polemizado.

\section{A Enfermagem Baseada em Evidências como um movimento e um discurso a ser problematizado}

A tarefa de problematizar qualquer discurso que tem o potencial de definir modos de ser profissional é de extrema responsabilidade. Mas muitas são as possibilidades de exercitar tal problematização, seja considerando algumas posições deste debate e bibliografias clássicas na divulgação deste movimento (3) , seja na discussão das PBEs em seu estatuto proposto - de disciplina ou novo paradigma. Referências que a situam como disciplina jovem e com impactos apenas inicialmente validados $(4,5)$ não apresentam os critérios usados para tal consideração. A incursão por alguns textos da MBE torna notável, embora não argumentada, uma intencionalidade de situá-la como disciplina científica e não apenas escolar. A mais recorrente forma de apresentar a MBE, entretanto, é como Paradigma emergente.

No entanto, o que se observa de novo é uma mudança do valor atribuído a certos elementos da clínica tradicional em favor de valores ligados às novas exigências, que podem ser colocadas em termos de condições da
"Como chancelar um saber e uma prática, abrigando-os do olhar de estranhos?" do sujeito contemporâneo, ou modos valorizados de ser que se autoconstrói como cidadão autônomo e saudável.

Um saber que se alçou a uma categoria superior não com base nas relações que estabelecia com o "outro" (humano), mas pela verdade que podia descobrir no outro (a doença como objeto), agora deve dar conta de justificar sua superioridade num tempo de tantas e relativas verdades. A chancela não mais pode ser atribuída à simples competência e razão individual; a mística do profissional deve ser transferida e conferida ao que pode realmente a sustenta - a medicina, a enfermagem, a tecnologia. O profissional é a conexão com este vasto saber construído em rede, em progressão acelerada, simultânea e auto-regulada. A imponderabilidade cede lugar à lógica da disposição ordenada, à regulação de entrada no acervo, de sua composição e de seu manejo, para os mesmos fins há muito postos pela clínica.

A mística da profissão, por sua vez, será ainda mais concretizada por meio e no interior da ciência, ou melhor, da pesquisa, aqui situando a mudança de uma cultura da ciência para uma cultura da pesquisa, tensionada por interesses, jogos de poder, políticas e instituições ${ }^{(7)}$. No entanto, mesmo neste aspecto as diferenças das PBEs em relação às práticas clínicas tradicionais podem ser consideradas apenas contingenciais. Como contingenciais, e não substantivas, podese pensar nas facetas que demarcam este panorama do saber e prática. Substancial é a incerteza, contingencial são os modos de viver com ela; substancial é o desconhecimento e o risco, contingenciais são as precauções e sociedade de comunicação, como a rapidez, facilidade de acesso e obsolescência da informação, sua circulação desterritorializada, a pluralidade e convivência de referências contrastantes, entre outras. É de se imaginar que diferentes riscos passam a ser enfrentados por uma corporação profissional impelida a garantir posições de status científico-social ou de hegemonia e monopólio de discursos e práticas sobre a doença. A clínica tradicional seria capaz de sustentar tais posições, frente a tantas ameaças, como a da insuficiência de estratégias de controle sobre a qualidade da prática? Como chancelar um saber e uma prática, abrigando-os do olhar de estranhos? Como assegurar a uma sociedade "conectada" que a medicina/enfermagem pode ser representada por aquele indivíduo particular, o profissional presente na ação singular? Como este profissional poderá corporificar a onipresente (mas desencarnada) força da moderna medicina/enfermagem? Como, em olhos e mãos visíveis, pôr em ato um saber tão emblemático?

Uma sociedade conectada não apenas está mais a par dos recentes avanços das tecnobiociências ou de suas polêmicas, como também tem disponível uma informática para seu consumo em saúde e bem-estar (ISC), com meios de apoio à decisão e aquisição em saúde que integram as chamadas tecnologias de informação de comunicação (TICS) ou a chamada e-saude - conteúdos de saúde em redes eletrônicas de informação ${ }^{(6)}$. Sem aprofundar na descrição deste cenário de "ascese" do paciente ao saber da e-saude, é preciso não desvinculá-lo de processos de construção formas de administrá-los. Assim, também:

- substancial é a intensa incorporação tecnológica que ultrapassa a cisão natureza-cultura e humano-máquina, produzindo subjetividades novas no interior de redes de comunicação, de linguagem e de consumo, enfim de todo um conjunto de dispositivos da tecnocultura, na qual o trabalho em saúde se integra; contingencial é a apresentação destas mudanças em efeitos de linguagem e construções discursivas filiadas a corporações, ideologias e projetos político-técnicos específicos (encarregados de enfrentar crises e novas exigências na preservação de antigas sustentações e modelos);

- substancial é a consolidação de um saber sobre a doença e para a manipulação da vida, de regras de acesso, domínio e aplicação deste saber em práticas controláveis; enquanto contingenciais são as hierarquias e status de autoridade, os métodos empregados para o julgamento e decisão, os guias para a valoração de argumentos, os critérios de credibilidade e controle interno;

- substancial é a relação operacional de disciplinas no esforço para suprir de organicidade e completude (biopsicosocial) um saber sobre a doença, enquanto contingencial são os acordos e arranjos provisórios que estas relações irão permitir de tempo em tempo, em zonas de negociação e litígio, de emergência de conceitos e explicações mais ou menos concorrentes ou coerentes entre si;

- substancial é a primazia do diagnóstico sobre a 
terapêutica/cura, enquanto contingenciais são os processos e aparatos que dirigem e moldam estes atos em si. Mesmo que operada por novos aparatos tecnológicos, a clínica não deixou de ser a clínica, não deixou de produzir diagnósticos em uma grade nosológica. A diagnose e o sistema terapêutico da biomedicina não são valorizados de modo idêntico, especialmente pela própria corporação, de onde se evidenciaria um traço característico desta racionalidade - o descompasso entre o projeto científico do estudo das doenças e o projeto ético da terapêutica ${ }^{(8)}$.

A MBE/EBE mudou tal lógica ou apenas estabeleceu novos pontos de apoio para este funcionamento, no que se poderia chamar de hiperclínica ou ciberclínica - expressão aqui escolhida para destacar a relação com a clínica tradicional.

No que se refere a uma aparente sucessão histórica, cabe pensar que a clínica, embora surja como o eixo mais antigo de apreensão da doença como objeto, não apenas permitiu e alimentou o desenvolvimento dos outros eixos (fornecendo as observações, descrições e materiais empíricos) como deles se serviu para evoluir como prática cientificamente embasada. Ou seja, longe de uma sucessão e superação há uma incorporação e retroalimentação-a hiperclínica das Práticas Baseadas em Evidências ampliaria o potencial "científico" e de sucesso ao inserir - caso/observação particular (categoria e método) numa série de casos aferidos por métodos estatísticos hierarquicamente valorados (indicativos do poder de persuasão e confiabilidade das evidências). De certa forma, atenuam-se os limites do método observacional, especialmente em sua versão mais individual, pela agregação do saber epidemiológico e de seus procedimentos, inclusive o método experimental. Os aportes da observação não são desprezados, mas perdem valor quando não chancelados pela expertisse (conquistada não tanto pela experiência clínica, mas em investigações credibilizadas) e por consensos, preferencialmente institucionalizados (comitês, associações, centros de pesquisa).

A este conjunto de atos que desenham o contato do profissional com o paciente - a anamnese e o exame - se acresce uma nova etapa, a de busca de melhores evidências para embasar o julgamento. A autoridade desloca-se para experts a serem consultados, não mais pelo contato face a face com os mais antigos, mas pela acessibilidade a bancos de dados informatizados e redes destinadas a revisar, sintetizar ensaios clínicos disponíveis, produzindo sistematizações mais acessíveis e traduzíveis à pratica. Não só produções científicoacadêmicas tradicionais, mas também experts, consumidores e uma infinidade de pacotes de instrumentais técnicos (webembalados) são produzidos e ofertados nesta rede de consumo.

Este novo momento do trabalho clínico não representa uma simples continuidade ou complemento - ele também altera os atos anteriores, já que impõe direcionalidade em todo o processo. É claro que tal implicação não é absoluta, mas variável e sutil. Até que ponto a preocupação em formular de maneira precisa uma pergunta (the well-balanced question) dirige o encontro com o paciente? Claro que fazer boas perguntas sempre foi a chave da investigação clínica, mas se este processo tinha como fim encontrar a resposta, o desfecho agora é adiado e remetido a um outro oráculo, mais confiável e representativo do potencial da medicina - o acervo da pesquisa clínica. Onde se interrompe o momento privado, na intimidade e autonomia da consulta, começa a sucessão de etapas da PBE, amplamente divulgadas em textos e sites institucionais ${ }^{(9)}$.

A hiperclínica ou ciberclínica que se desenvolve no interior e por meio da MBE/EBE pode sinalizar para transformações quando pensada em termos da categoria central da clínica (do "caso" para os "casos sistematizados e validados") e de seu método (da observação para a análise probabilística). Então, é razoável supor um movimento ou intenção de contrastar definições e estatutos defendidos pela PBE e até, em certo sentido, falar de uma ideia de hiperclínica/ciberclínica como expressão que evidencia não uma ruptura fundamental com modelos anteriores, mas uma sobrevivência e expansão em novos ambientes.

Em suma, esta é uma atitude a favor da constrastação e da problematização. Sim, é importante que possamos imaginar outros modos de olhar para qualquer coisa que se apresente tão carregada de autoridade e unidade. Em segundo lugar é preciso romper com qualquer hipótese de totalização e verdade. Por que precisamos de explicações, referências e projetos tão unitários? Ou por que uma forma de nomear ou falar tem que ser alçada à condição de tamanha credibilidade? Por que temer tanto nossas situações contraditórias, nossas referências insuficientes e nossos sensos de identidade precários e fragmentados?

O interesse em discutir a PBE se deu por tomá-la como uma vertente tecnológica em expansão, tanto em termos de adeptos e técnicos treinados, em veículos de disseminação ou em prestígio acadêmico. A importância de discussões sobre nossas escolhas tecnológicas é inegável, mas o caminho aqui tomado se deu por razões mais localizadas - o de inserir o tema da "formação ética/ moral" no interior de um dispositivo da formação profissional.

A maioria dos textos dedicados à $\mathrm{PBE}$, especialmente a MBEeEBE, usa termos como educação e ensino para destacar a importância de sua incorporação nos processos formais de formação e em alternativas de capacitação permanente. A disseminação da PBE é vista como indispensável ao exercício da moderna e qualificada prática profissional em saúde e a formação é condição para tal. Para isso, cenários clínicos de ensino prático (instituições de estágios e residências), professores-instrutores e instrumentos tecnológicos devem estar preparados e adequados. É reclamada uma reforma tecnológica dos processos educativos e lócus da formação universitária atinge prioridade máxima.

Apesar do uso dos termos ensino e formação, é útil adotar o termo socialização, mesmo reconhecendo as várias vinculações às teorias sociológicas e psicológicas. Aqui se considera a socialização como "um processo de construção, desconstrução 
e reconstrução de identidades ligadas às diversas esferas de atividades (principalmente profissional) que cada um encontra durante sua vida e das quais deve aprender a tornar-se ator"(10). Um dos motivos de tal adoção é destacar a socialização como o processo responsável pela relativa estabilidade dos grupos e estilos de pensamento, que inclui internalização de valores e normas, desenvolvimento de habilidades específicas como a capacidade de perceber fenômenos. Fleck ${ }^{(11)}$ diferencia o "ver confuso e inicial" do "ver formativo" direto e desenvolvido (observar científico), possibilitado por uma base teórico-prática e experiência prévia no campo específico. A habilidade para perceber fenômenos de acordo com um estilo leva à perda da capacidade para ver o que conflita com este perceber orientado (harmonia de ilusões), queéa raiz de todo estilo de pensamento ${ }^{(12)}$.

O projeto educacional das PBEs assume a conformação de uma ampla socialização de futuros profissionais (sem excluir os que já exercem) com base na aquisição de qualidades que o identificariam a um ideal profissional de competência e cientificidade. Talvez como nunca antes na história destas práticas (medicina e enfermagem) se tenha chegado a um dispositivo ou modelo de ação tão potente em sua capacidade de expansão e de regulação interna. O controle que se estabelece é de uma nova ordem, pela via desta socialização que situa cada indivíduo numa rede de consumo de produtos prontos para o uso (aplicáveis nas intervenções cotidianas). Em nossas atuais redes de informação tão abertas, os riscos da oferta de produtos não confiáveis pode ser neutralizado pelo treinamento massivo de seus consumidores.

O controle é dado de modo extensivo - incontáveis profissionais lendo, interpretando, julgando, selecionando de acordo com os mesmos critérios, guias e escalas - e intensivo, cada um tendo seus procedimentos rigorosamente autovigiados, por referência a um ideal regulador assimilado e continuamente mobilizado.

A chave para tamanha funcionalidade é, sem dúvida, a eficácia deste mito identitário, a crença nos seus supostos e métodos como algo "a que não se pode fugir", sob pena de retroceder no tempo. A favor desta crença ainda há poucos estudos de avaliação e menos ainda com resultados mensuráveis da aplicação de evidências nas intervenções clínicas. Já se propõe, no entanto, uma referência para guiar este tipo de avaliação, envolvendo avaliação de estudantes, intervenções e resultados. Os aprendizes são classificados em "doers" (desenvolvem todos os passos do processo), usuários (elaboram questões clínicas e buscam literatura pré-avaliada) e replicadores (seguem recomendações de líderes) ${ }^{(13)}$.

\section{Considerações finais: o desafio ético de nossas tecnologias em muitos casos mais a problematizar}

A tecnologia não é neutra. Estamos dentro daquilo que fazemos e aquilo que fazemos está dentro de nós. Vivemos em um mundo de conexões - e é importante saber quem é que é feito e desfeito ${ }^{(14)}$.

Os sentidos - sociológico e epistemológico - apontados no termo socialização ajudam a esclarecer o contexto educacional que envolve a disseminação de tecnologias para a ação em saúde, mesmo que não representem a opção teórica aqui adotada. Ao considerarmos o papel das tecnologias (de educação e trabalho) na forma como o sujeito adquire e expressa a experiência de si, em possíveis narrativas construídas também no e a partir do trabalho, há que se ponderar o impacto de tecnologias como a PBE no processo de fabricação da experiência subjetiva tão fundamental ao tema da ética.

Ao produzir um saber específico, a medicina ou a enfermagem não escapam à particularidade de seu "conhecer" possuir como meta uma intervenção, uma necessidade concreta de sucesso, com base em modelos explicativos existentes e sempre desafiados pela variabilidade da doença; variabilidade que não reside apenas no corpo enfermo e que gera uma insuficiente e insatisfatória relação com as observações disponíveis (11). A EBE/ MBE é também, de certa forma, uma resposta a esta variabilidade, a esta insuficiência e volatilidade na relação com os dados da observação. É uma busca de solidez frente às contingências da vida e da doença, ou das possibilidades de controle da vida e da doença.

Poderíamos pensar a MBE como o sucedâneo mais ou menos lógico e aperfeiçoado tecnologizado e processado na linguagem da cibercultura - da velha clínica e de seu projeto político e técnico de intervenção sobre o social?

A clínica se solidificou nos espaços institucionalizados de prática e ensino, no interior do hospital-escola, pelo precoce contato com o doente e sob o exemplo do mestre. Os aparatos terapêuticos e pedagógicos que trabalharam para a emergência e consolidação da clínica também produziram interações sociais e formas discursivas, não apenas como saberes cientificamente formalizados, mas também como novos significados impostos. Junto com a ferramenta, cria-se também um mito.

Algumas mudanças e ampliações dos cenários, alguns novos ou complexificados instrumentos tecnológicos, mas ainda uma mesma meta e um mito revitalizado ao extremo, elevado ao seu potencial high tech, ao sucesso calculado no nível do provável.

Nesta discussão nenhuma tendência tecnológica ou discurso de mudança da prática e do ensino pode ser tomado como única ou unânime, ao contrário, precisa ser localizada em contextos de disputa, coexistência de elementos de projetos contraditórios em arranjos precários e ambíguos. Se a vertente da EBE/MBE se mostra uma tendência em crescente fortalecimento e valorização, outras alternativas são visualizadas e implementadas. Até que ponto são conciliáveis ou excludentes? Em que níveis se definem como inovadoras? Em que se diferenciam ou que bases compartilham?

Apesar das diferenças entre possíveis alternativas, experimentadas em mudanças institucionais, políticas específicas e projetos de formação, o que se pode compreender como comum é a produção de novas direcionalidades para o trabalho em saúde e, assim, da quebra de matrizes identitárias fixas podem emergir inesperadas construções e subjetividades.

O que Teixeira ${ }^{(15)}$ chama de "disposições ético-cognitivas" ou "estados do corpo", também poderíamos denominar, a partir 
de diferentes linguagens do campo do conhecimento, de conjunto de competências, de exigências morais, de demandas identitárias, de experiências de si, de referências de autoreflexividade ou de dimensões ético-políticas da subjetividade. $\mathrm{O}$ que mais importa destacar é que o ponto de vista ético passa a ocupar um lugar a partir do qual outras perguntas podem ser formuladas. Por exemplo, a noção de inovação é radicalmente diferente se pensada a partir do ponto de vista ético: - $O$ que é novo por este modo de olhar? A EBE/MBE representa uma inovação em termos de "disposições ético-cognitivas"? Que tecnologias de trabalho e educação em saúde assumem seu papel na mediação da experiência de si daquele que opera a própria técnica? Que experiências de si são possíveis no interior e no funcionamento destas tecnologias?

Daí a EBE/MEB ocupar um lugar exemplar da produção de sentidos na formação em saúde. Sobre estes sentidos cabe questionar: A Enfermagem Baseada em Evidências é uma resposta à crise das práticas institucionalizadas de saúde?; Ou um novo mito tecnológico? (ou a atualização do antigo mito da clínica; Nestas práticas se produz um novo sujeito trabalhador?

Tais perguntas encerram o desafio ético que não pode ser desprezado na reflexão sobre a relação sujeito e tecnologia. Entre mito e instrumental existe uma mútua criação e, portanto, nossa crítica aos mitos deve ser reconfigurada a partir da própria posição como inventores, operadores e defensores de tecnologias. O mito aqui tratado pode assumir o sentido de ideal e, daí sua complicada e dúbia situação: - ser produtivo e desejado como mobilizador de projetos individuais e coletivos, de pulsões que impulsionam transformações; - facilmente tornar-se "doença do ideal", maciça e letal para a criação e o investimento subjetivo, produtiva de segurança e proteção frente ao desamparo e a angústia e, também, produtiva de sujeitos seduzidos por uma imagem, heterônomos e "apegados a referências duras", presos às armadilhas de uma falsa onipotência ${ }^{(16)}$.

Assim, a pergunta acima não pretende se fechar em um único sentido, positivo ou negativo, acerca de ideais, mas pretende dizer de uma possibilidade de nos recolocarmos frente aos ideais individuais e coletivos que nos constituem. Também o sujeito trabalhador construído na emblemática da MBE/EBE/ PBE não pode apenas sofrer novos processes de identificação - como trabalhador novo ou velho, mais ciborguizado, mais instrumentalizado/armado, mais "conectado", mais científico, mais padronizado, mais controlado, mais tecnificado. A problematização do que somos - neste tempo, nesta cultura, neste trabalho, nesta família - não é um dependente de nossa posição frente a discursos mais ou menos críticos, é condição desta atitude de perplexidade, desconforto e liberdade, que Foucault apresenta como atitude ética interessante.

Esta pode ser uma inspiração para pensarmos a aparente encruzilhada das tecnologias no campo da saúde: longe de um esgotamento da clínica, de sua superação ou, no outro extremo, de sua continuidade linear, possamos pensar em transições e aperfeiçoamentos metodológicos no seio do pensamento biomédico. Pensar sim em suas insuficiências, mas também em seu empenho por manter eficazes instrumentos úteis de abordagem da doença. Criticar pretensões e excessos de seu discurso e ação, mas não pensar que podemos prescindir de seu funcionamento. $\mathrm{Ou}$, como mais radicalmente expressa F. Scott Fitzgerald:

Toda vida é, desde cedo, um processo de demolição [...] A marca de uma inteligência de primeiro plano é a capacidade para concentrar-se em duas ideias contraditórias sem perder a possibilidade de funcionar. Por exemplo, deveríamos poder compreender que as coisas carecem de esperança, e não obstante estar resolutos a transformá-las (17).

Com isso, talvez possamos situar discursos e projetos tidos como mais ou menos inovadores, mais ou menos conservadores, em um terreno no qual a complexidade das necessidades - de saúde, mas também do trabalho social, da ciência e da tecnocultura - impõe a convivência, sempre tensionada, entre visões e intervenções diferentes.

\section{Referências}

1. Ramos FRS, Do OJR. Bioética e identidade profissional: a construçăo

de uma experiência de si do trabalhador da saúde. Interface Comunic

Saúde Educ. 2009;13(29):259-70.

2. Castiel LD, Póvoa EC. Medicina baseada em evidências: novo paradigma assistencial e pedagógico. Interface Comunic Saúde Educ. 2002;6(11):117-32. 3. Evidence-Based Medicine Working Group. Evidence-based medicine - a new approach to teaching the practice of medicine. Jama. 1992;268(17):2420-5. 4. Sackett DL, Rosenberg WMC, Gray JAM, Haynes RB, Richardson WS. Evidence based medicine: what it is and what it isn't. BMJ. 1996; 312:71-2.

5. Guyatt G, Cook D, Haynes B. Evidence based medicine has come a long way. BMJ. 2004;329:990-1.

6. Castiel LD, Vasconcellos-Silva PR. Internet e o autocuidado em saúde: como juntar os trapinhos? Hist Ciên Saúde-Maguinhos. 2002;9(2):291-314,

7. Castiel LD. Réplica aos debatedores: $O$ bebê e a água do banho. Interface

Comunic Saúde Educ. 2002;6(11):129-30.

8. Camargo Jr KR. A biomedicina. Physis (Rio J.). 2005;15(supl):177-201.

9. Dubar C. A socialização - construção das identidades sócias e profissionais. São Paulo: Martins Fontes; 2005.

10. Centre For Evidence-Based Medicine [Internet]. [citado em 2010 Mar 02]. Disponivel em: http://www.cebm.net

11. Fleck L. La genesis y el desarrollo de un hecho cientifico.

Madrid: Alianza; 1986.

12. Gonçalves JR, Matos E, Ramos FRS. A epistemologia de Ludwick Fleck:

subsídios para a prática interdisciplinar em saúde. Texto Contexto Enferm. 2005;

14 (3): 383-390.

13. Ciliska D. Evidence-based nursing: how far have come? What's next?

Evid-Based Nurs. 2006;9:38-40.

14. Kunzru H. Você é um ciborgue: um encontro com Donna Haraway.

In: Silva TT, (organizadora). Antropologia do ciborgue: as vertigens do

pós-humano. Belo Horizonte: Autêntica; 2000.

15. Teixeira RR. A grande saúde: uma introdução à medicina do corpo sem

órgãos. Interface Comunic Saúde Educ. 2004;8(14):35-72.

16. Sá MC. Subjetividade e projeto coletivos: mal estar e governabilidade nas organizaçōes de saúde. Ciên Saúde Coletiva. 2005;6(1)151-64.

17. Canguilhem G. Escritos sobre la medicina. Buenos Aires: Amorrortu; 2004. 


\section{Enfermeiros, Técnicos e Auxiliares de Enfermagem, não temos palavras para agradecer. Temos gestos.}
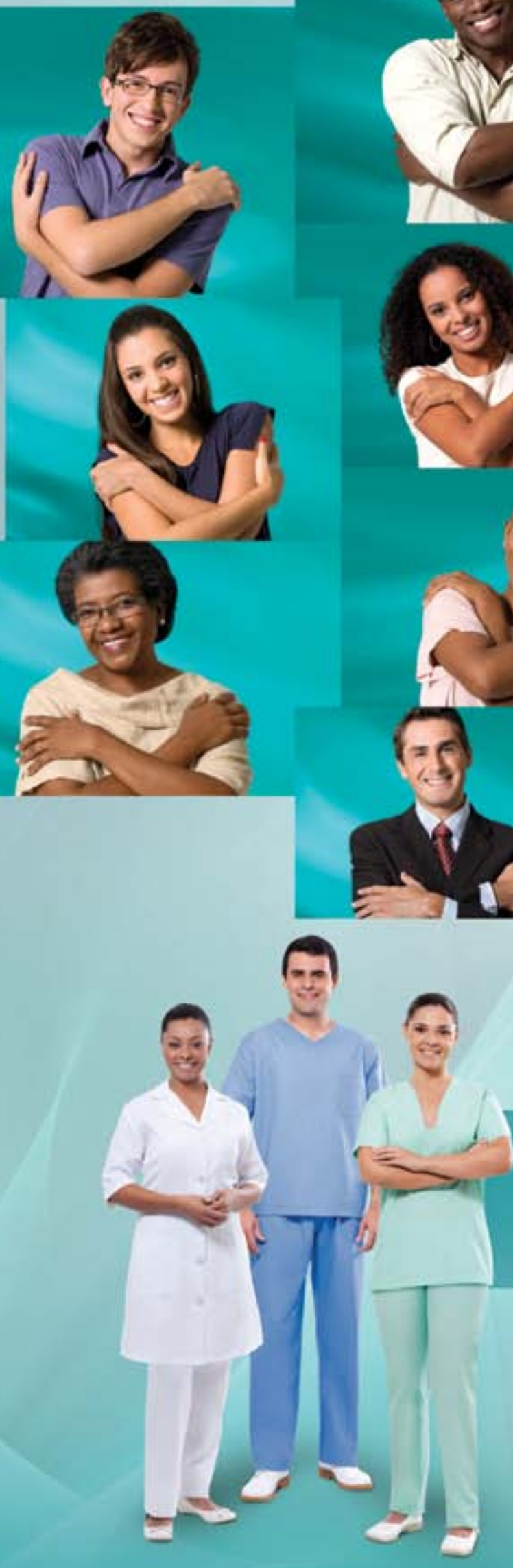
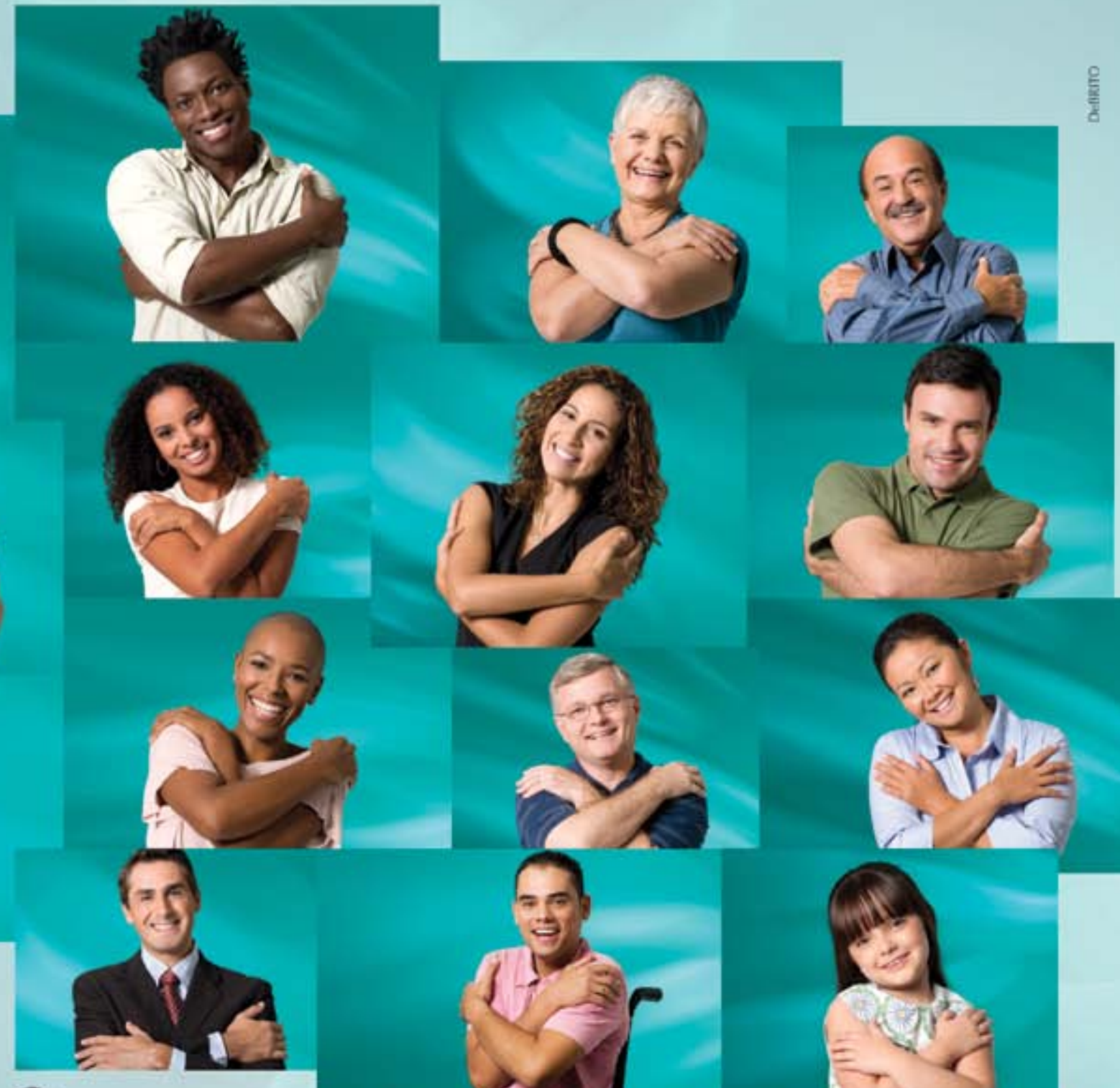